73rd Conference of the Italian Thermal Machines Engineering Association (ATI 2018), 12-14 September 2018, Pisa, Italy

\title{
The influence of thermal bridge calculation method on the building energy need: a case study
}

\author{
Stefano Bergero ${ }^{\mathrm{a}}$, Anna Chiari ${ }^{\mathrm{a}, *}$ \\ ${ }^{a}$ DAD - Department of Architecture and Design, Polytechnic School, University of Genova, Stradone S. Agostino 37, 16123, Genova, Italy
}

\begin{abstract}
The goal of the paper is to compare two different methods of calculating the linear transmittance of thermal bridges in order to evaluate the building energy need for heating. As a case study, it was considered an existing non-isolated residential building of '70 years consisting of 30 housing units. All the construction details of the building are known. The energy analysis of the building was carried out using a commercial software. The linear transmittance of the thermal bridges was determined both by the catalogue, provided by the software itself, and by the numerical finite-element evaluation according to UNI EN ISO 10211 standard using a 2-D numerical simulator. Through numerical analysis it is possible to evaluate in a detailed way all the thermal bridges present in the building and therefore it is possible to evaluate the approximation induced by the use of the catalogue. Results show that the detailed analysis leads to a transmission heat exchange through thermal bridges about eight times greater than that estimated through the catalogue and consequently to a higher building energy need of about $12 \%$. The heating energy needs per unit area of the individual housing units were also compared.
\end{abstract}

(C) 2018 The Authors. Published by Elsevier Ltd.

This is an open access article under the CC BY-NC-ND license (https://creativecommons.org/licenses/by-nc-nd/4.0/)

Selection and peer-review under responsibility of the scientific committee of the 73rd Conference of the Italian Thermal Machines Engineering Association (ATI 2018).

Keywords: thermal bridges, linear thermal transmittance, 2-D numerical simulation, building energy need, heat accounting.

\footnotetext{
* Anna Chiari. Tel.: +39-010-209-5877; fax:: +39-010-209-5905.

E-mail address: anna.chiari@unige.it
} 


\section{Introduction}

In Italy, according to the Art. 3 of Legislative Decree 192/05 [1], the calculation procedure of the buildings energy performance, prepared in compliance with the EN standards to support Directives 2002/91/EC [2] and 2010/31/EU [3], is provided by the UNI/TS 11300 technical specifications series. In particular UNI/TS 11300-1 standard [4] provides the method to determine the building envelope energy need $\mathrm{Q}_{\mathrm{H}, \mathrm{nd}}$, considering heat transfer by ventilation and transmission and solar and internal heat gains. The heat transfer through thermal bridges is determined by the linear thermal transmittance $\psi$ and affects the transmission heat transfer towards the external environment, the unconditioned spaces and the ground.

The UNI/TS 11300-1 standard establishes two methods for determining the $\psi$ value for both new and existing buildings:

- numerical calculation, according to UNI EN ISO 10211 standard [5];

- thermal bridges catalogues, carried out in compliance with UNI EN ISO 14683 standard [6].

For new and fully refurbished buildings, when all construction details are known, numerical calculations give the most precise value of $\psi$. In the case of existing buildings, however, precise information on the joints between the building elements is not always available and the linear transmittance can be determined by comparing the particular detail with the best fitting example from a thermal bridge catalogue.

The main commercial software contain a catalogue which provides the $\psi$ values of the main thermal bridges, but which does not cover all the types present in the building. In this case the technicians who compile the diagnosis and the energy certification of buildings usually either neglect such thermal bridges or look for expedients in order to take into account their contribution, with consequent errors in their evaluations. Moreover, depending on the constructive type of building, the weight of thermal bridges on energy need can be particularly significant [7] and therefore using different calculation methods or making simplifying assumptions can lead to inaccurate results.

In the present paper a case study is considered in order to evaluate the influence of the linear transmittance calculation method on the envelope energy need of a residential building. More than forty types of thermal bridges have been considered, calculating the $\psi$ value with both above mentioned methods, i.e. numerical calculation and thermal bridges catalogue. Comparison was obtained with reference to both the needs of entire building and each housing unit, distinguishing between the apartments located on the first and the last floors and those located on the intermediate floors. Results are particularly significant also for the application of the Italian UNI 10200 standard [8],

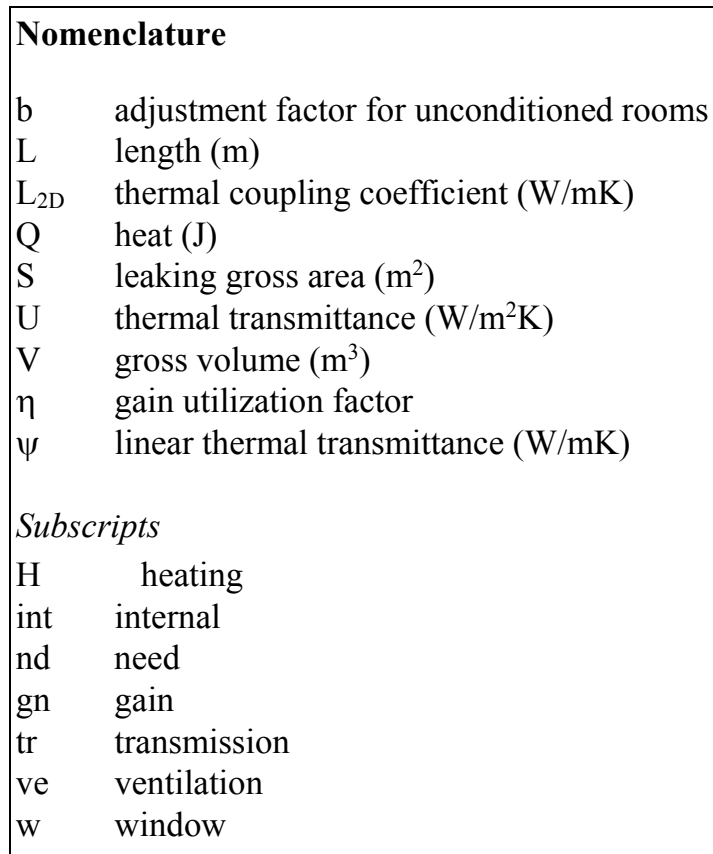


concerning the subdivision of expenses in condominiums equipped with centralized heating systems and with thermal control and heat metering devices. In fact, this rule provides that the costs related to the involuntary consumption due to plant generation and distribution energy losses and to the plant management and maintenance is divided on the basis of millesimal tables based on the envelope energy needs $Q_{H, n d}$ of single apartments. A precise calculation of the contribution of thermal bridges allows a more equitable division of expenses between the different occupants.

\section{Case study}

A cooperative residential building, built in 1973, located in the outskirts of Novi Ligure (AL) and consisting of 3 distinct blocks each on 5 levels, has been considered, as shown in Fig. 1.

On the ground floor there are the portico and the cellars. The upper floors are divided, for each block, into two apartments, one of about $82 \mathrm{~m}^{2}$ and the other of about $101 \mathrm{~m}^{2}$ of useful floor area, as shown in Fig. 1, for a total of 30 apartments. The roof is pitched; below there is a not habitable attic bordering the last floor. The main building geometric parameters are reported in Fig. 1.
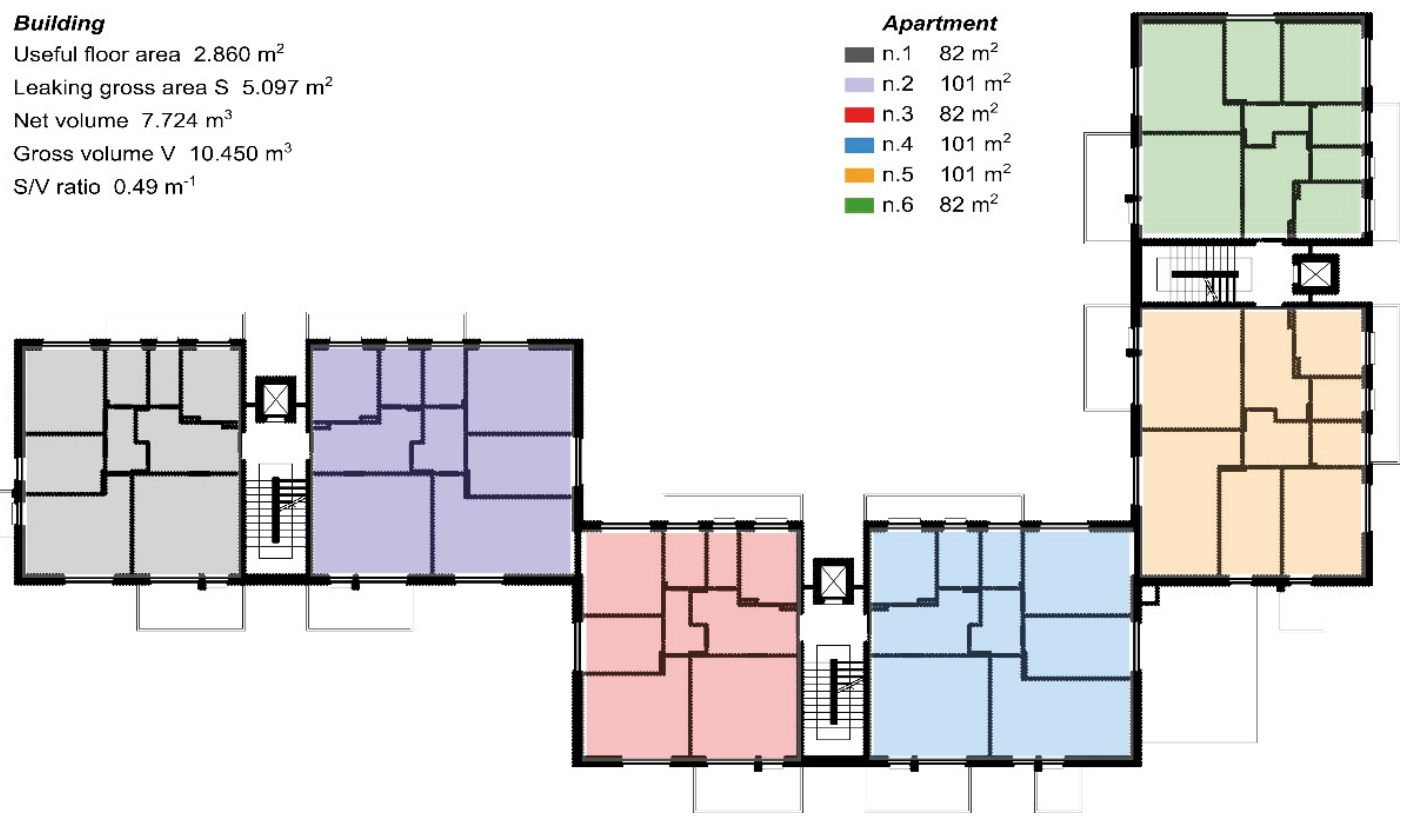

Fig. 1. Plan of a typical building floor.

The main features of the building envelope are listed below:

- the skeleton is a frame with beams and pillars in reinforced concrete; the curtain walls are in masonry with an empty box ( $8 \mathrm{~cm}$ gap) in perforated bricks;

- doors and windows are made with metal frame without thermal break and single glazing; roller shutters with noninsulated boxes are present;

- the slabs are in masonry with bricks and cement;

- all buildings elements both horizontal and vertical, which separate the heated zone from the outside environment or from unconditioned spaces (attic, cellars, stairwell), are not insulated.

The details of the building elements and thermal bridges have been obtained from inspections and design documents. Thermal conductivities of construction materials are provided by the standards UNI 10351 [9], UNI EN ISO 10456 [10] and UNI/TR 11552 [11]. Thermal properties of doors and windows are derived from UNI EN ISO 10077-1 [12]. Conventional surface and air gap resistances of UNI EN ISO 6946 [13] are used.

Heat exchange area and corresponding thermal transmittance of different elements of the building envelope are shown in Table 1, for both walls and windows. 
Tab. 1. Heat exchange area and thermal transmittance of building elements.

\begin{tabular}{lcc}
\hline Building element & Area $\left[\mathrm{m}^{2}\right]$ & Transmittance $\left[\mathrm{W} / \mathrm{m}^{2} \mathrm{~K}\right]$ \\
\hline External wall & 1615.8 & 0.94 \\
Sub window wall & 220.0 & 1.76 \\
External stairwell wall & 152.6 & 2.31 \\
Internal stairwell wall & 631.7 & 2.50 \\
Floor towards cellars & 343.5 & 1.35 \\
Floor towards portico & 312.6 & 1.63 \\
Floor towards attic & 658.6 & 1.72 \\
Apartment security doors & 50.4 & 1.12 \\
Roller shutter boxes & 183.0 & 6.00 \\
Windows and door windows & 473.2 & $5.91 \div 6.02$ \\
\hline
\end{tabular}

\section{Calculation methodology}

This chapter describes the methods used to determine the building energy need for heating and the thermal bridges linear transmittance.

\subsection{Building energy need for heating}

The building energy need for heating is carried out by the commercial software EC700 of EDILCLIMA ${ }^{\circledR}$ softwarehouse [14], in compliance with the UNI/TS 11300-1 standard, based on monthly calculation method [15].

For each apartment, which constitutes a thermal zone of the building, the monthly energy need for heating $\mathrm{Q}_{\mathrm{H}, \mathrm{nd}}$ is given as follows:

$$
\mathrm{Q}_{\mathrm{H}, \mathrm{nd}}=\left(\mathrm{Q}_{\mathrm{H}, \mathrm{ve}}+\mathrm{Q}_{\mathrm{H}, \mathrm{rr}}\right)-\eta_{\mathrm{H}, \mathrm{gn}}\left(\mathrm{Q}_{\mathrm{int}}+\mathrm{Q}_{\mathrm{sol}, \mathrm{w}}\right)
$$

$\mathrm{Q}_{\mathrm{H}, \mathrm{tr}}=$ total heat transfer by transmission, determined considering heat transfer towards external environment ad unconditioned spaces, including the solar heat gain of opaque elements and the extra heat flow due to thermal radiation to the sky

$\mathrm{Q}_{\mathrm{H}, \mathrm{ve}}=$ total heat transfer by ventilation, determined considering natural ventilation

$\eta_{\mathrm{H}, \mathrm{gn}}=$ gain utilization factor

$\mathrm{Q}_{\text {int }}=$ internal heat gain

$\mathrm{Q}_{\mathrm{sol}, \mathrm{w}}=$ solar heat gain of glazed components, determined considering all external obstacles (other buildings, vertical and horizontal overhangs)

Transmission heat transfer is calculated by the overall heat transfer coefficient of the zone $\mathrm{H}_{\mathrm{tr}, \mathrm{adj}}$, adjusted for the indoor-outdoor temperature difference that includes the effect of linear thermal bridges. Temperatures of unconditioned spaces are determined in simplified way by means of adjustment factor $b_{\text {tr }}[15]$. $b_{\text {tr }}$ values of $0.6,0.9$ and 0.8 towards stairwell, attic and cellars respectively are assumed.

\subsection{Thermal bridges linear transmittance}

The thermal bridges linear transmittance $\psi$ has been calculated by the two following methods:

- thermal bridge catalogue provided by EC700 software and based on the Thermal Bridges National Abacus [16];

- 2-D numerical calculations carried out by finite-element simulator THERM, developed at Lawrence Berkeley National Laboratory (LBNL) [17]. Linear transmittance is provided by the following relation:

$$
\psi=\mathrm{L}_{2 \mathrm{D}}-\sum_{\mathrm{i}} \mathrm{L}_{\mathrm{i}} \mathrm{U}_{\mathrm{i}}
$$


where $\mathrm{L}_{2 \mathrm{D}}$ is the thermal coupling coefficient obtained from the 2-D calculation of the component separating the two environments being considered, $U_{i}$ is the thermal transmittance of the 1-D i-th component, separating the two environments being considered, $\mathrm{L}_{\mathrm{i}}$ is the length over which the value $\mathrm{U}_{\mathrm{i}}$ applies. Numerical method has been previously tested and validated in accordance to case-studies A.1 and A.2 of Annex A of UNI EN ISO 10211.

All linear transmittances have been estimated referring calculations to external measures, according to UNI EN ISO 14683 and EC700 input data system.

All construction details of the building under analysis are known. The catalogue of thermal bridges allows to quickly determine the $\psi$ value, which is very important in the economy of a professional job, but has some limitations that can lead to inaccuracy of results. The main limits are:

- the layout of the nodes is simplified: for example, in the case of the window thermal bridge, a single $\psi$ value is applied on the entire perimeter of the window (see Fig. 2, highlighted in red), neglecting the presence of the underlying marble slab and eventually overhead roller shutter box;

- the $\psi$ value is missing for some types of thermal bridges common in buildings: for example, there are no vertical thermal bridges that involve three temperatures (e.g. internal environment, external environment and stairwell) and that involve two or more different wall types, as the thermal bridge due to sub-window thickness reduction.

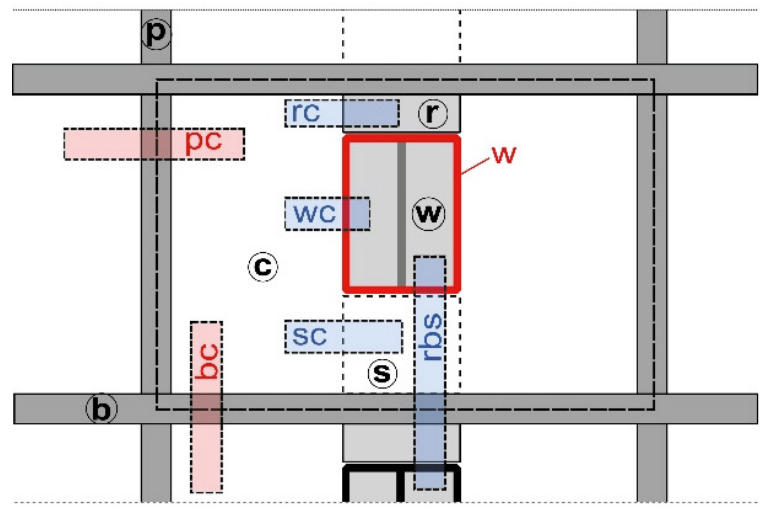

\author{
Building elements \\ $\mathrm{c}=$ current wall \\ $\mathrm{b}=$ beam \\ $p=$ pillar \\ $\mathrm{s}=$ sub window \\ $w=$ window \\ $r=$ roller shutter box
}

Fig. 2. Window thermal bridge.

In the present study two different approaches are considered in the energy need calculation. The first one is that of a technician who uses only the commercial software and therefore is forced to simplify the analysis or even to neglect the contribution of some thermal bridges; the second one is a rigorous approach that considers the contribution of all thermal bridges through the $\psi$ values derived from the numerical analysis. The second approach was very timeconsuming as it requires detailed drawing of all the joints present in the building envelope.

For example, in the case of window module sketched in Fig. 2, the detailed THERM analysis takes into account all the thermal bridges. Linear transmittances of three vertical termal bridges between the current wall and roller schutter box (rc), window frame (wc) and sub-window (sc) respectively have been calculated separately; than the mean linear transmittance of them has beeen determined. A single horizontal thermal bridge (rbs) that includes the window frame, the sub-window, the inter-floor slab and the roller shutter box has been modeled. For calculation details you can refer to [18].

More than forty types of thermal bridges that compete to the building envelope have been considered. Fig. 3 shows a selection of them, highlighting their location in the building. The THERM models and the calculated linear transmittances referred to external measures, concerning most the analyzed thermal bridges, are reported in [19].

Most of the thermal bridges shown in Fig. 3 are not present in the abacus (highlighted in blue) and therefore in the simplified calculation they have been omitted or returned to the most similar case present in the abacus. For example, when there is a balcony in a thermal bridge that involves three temperatures (e.g. internal environment, external environment and cellars), the thermal bridge has been simplified by neglecting the presence of the balcony. 

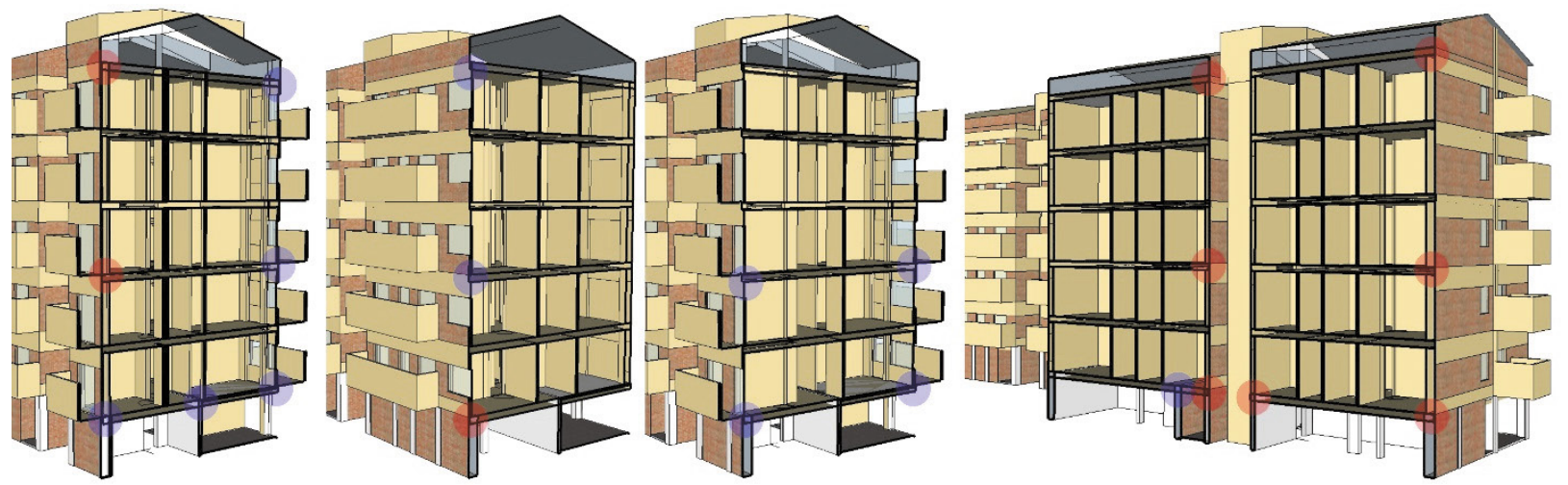

Fig. 3. Sketch of the building with the most significant thermal bridges.

\section{Results and discussion}

Fig. 4a shows the overall length of considered thermal bridges for different environments to which the heat exchange is directed for both evaluation methods, simplified according to the EC700 catalogue and analytical by THERM. Fig. 4b shows the corresponding thermal exchanges for transmission through thermal bridges only, calculated using the two methods. For thermal bridges that involve three temperatures, the lengths were attributed in equal parts to the two environments bordering the heated room for both simulation methods. Thermal exchanges were assigned in a different way: in the case of abacus calculation the evaluated linear transmittance of the whole thermal bridge is divided in half between the two environments, while two linear transmittances, one for each environment, are derived in the case of numerical calculation.

Fig. 4a reveals that the lengths of the thermal bridges towards the stairwell are identical for the two methods, while they differ slightly in the case of thermal bridges towards attic and cellars, e.g. thermal bridges with three temperatures that involve both attic or cellars and stairwell have not been considered in the catalogue calculation. A significant difference in length for thermal bridges towards the external environment is present, due mainly to doors and windows junctions, as explained in the previous chapter.

Fig. $4 \mathrm{~b}$ shows that numerical calculations lead to an higer weight of thermal bridges to the transmission heat transfer. The contribution of thermal bridges towards unconditioned rooms is negative for both calculation methods owing to the external measures system considered. Furthermore, this contribution is in absolute value negligible compared to that towards the outside environment. Finally, there is a significant difference between the two methods in the value of the thermal exchange to the outside environment: the contribution in the case of detailed calculation is more than three times that calculated by abacus. This discrepancy is mainly due to the detail of the thermal bridges relative to door windows and windows.

Fig. 5 shows the thermal exchange for transmission $\mathrm{Q}_{\mathrm{H}, \mathrm{r}}$, net of the opaque solar gain and extra heat flow to the sky, referred to the entire building and to the entire heating season divided between opaque and glazed components and thermal bridges for two calculation methods. It is observed that the contribution of thermal bridges in the case of numerical calculation is about eight times compared to the case of abacus calculation, with weight of thermal bridges equal to $12 \%$ and $2 \%$ respectively on the whole heat exchange by transmission. The corresponding building energy need $\mathrm{Q}_{\mathrm{H}, \mathrm{nd}}$ is also shown in Fig. 5: detailed calculations lead to an energy need higher than $12 \%$ of that calculated by abacus.

Finally, Fig. 6 shows the energy need per unit area of single housing units determined by numerical and abacus calculations. Obviously, the specific needs of the apartments on the first and last floor are greater than those of the apartments located on the intermediate floors. The percentage difference between the major and the minor specific energy need is $44 \%$ with the numerical method and $41 \%$ with the abacus calculation. It follows that for this condominium it is impossible to apply the legislative decree 18 July 2016, n. 141 [20] for the involuntary consumption cost distribution, but it is necessary to apply the standard procedure provided by the UNI 10200 [8]. 


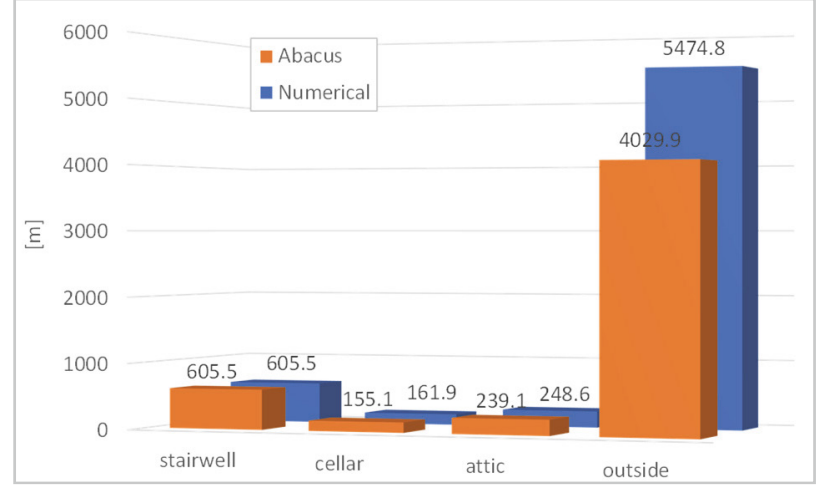

(a)

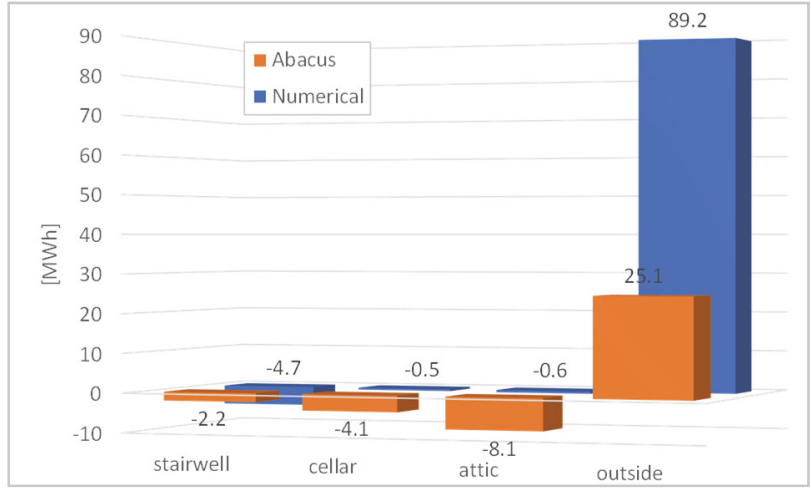

(b)

Fig. 4. Thermal bridges contribution for different adjacent environments: (a) length, (b) heat transfer by transmission.

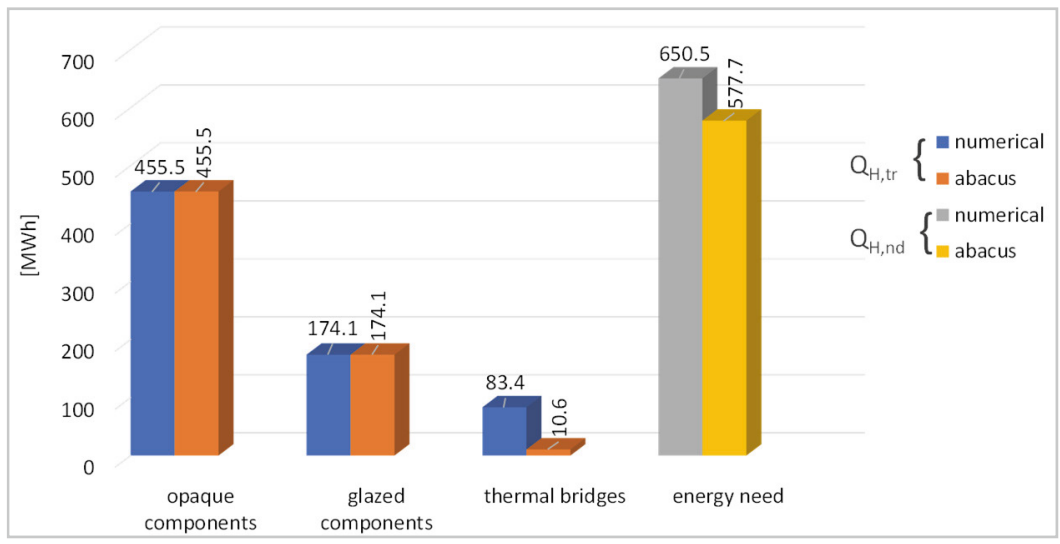

Fig. 5. Transmission heat transfer $\mathrm{Q}_{\mathrm{H}, \mathrm{tr}}$ and energy need for heating $\mathrm{Q}_{\mathrm{H}, \mathrm{nd}}$.

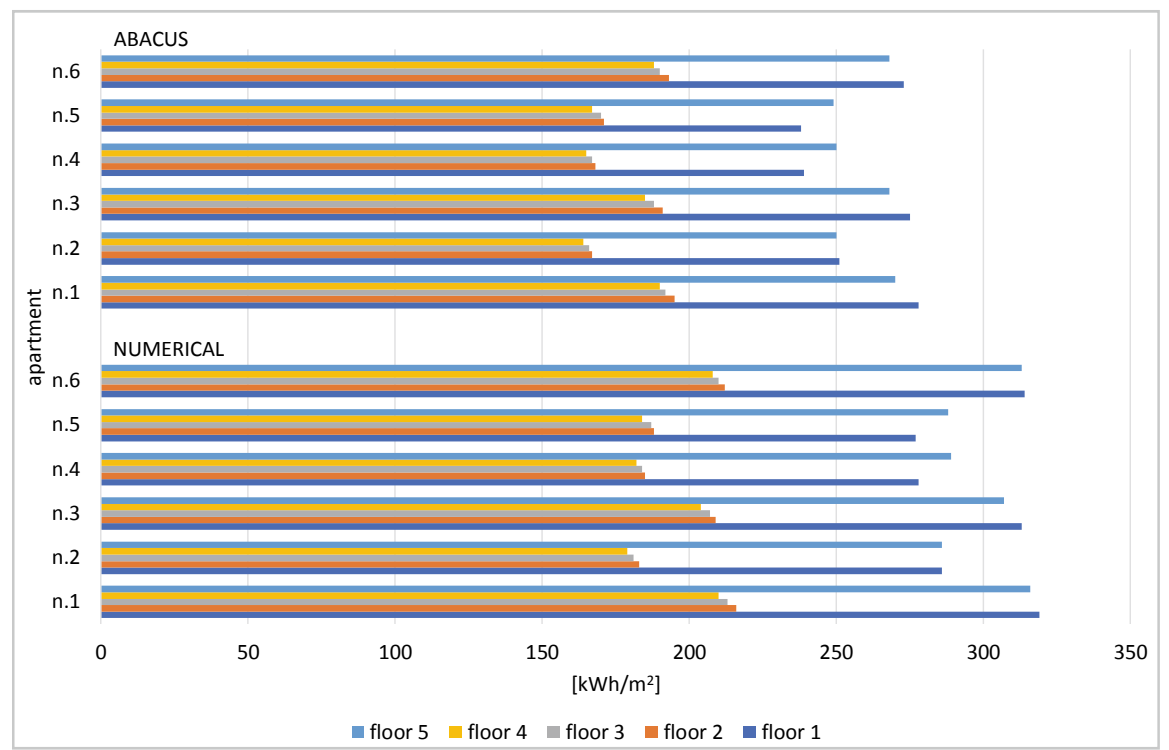

Fig. 6. Energy need per unit area of single housing units: abacus and numerical calculation. 


\section{Conclusions}

With reference to the examined case study, results point to the following conclusions:

- the contribution of thermal bridges towards the unconditioned environments is negligible compared to that towards the outside environment;

- detailed analysis leads to a transmission heat transfer through thermal bridges about eight times greater than that estimated through the catalogue; the weight of thermal bridges is equal to $12 \%$ and $2 \%$ respectively on the whole heat exchange by transmission;

- detailed calculations of thermal bridges lead to a building energy need $\mathrm{Q}_{\mathrm{H}, \mathrm{nd}}$ higher than $12 \%$ of that calculated by abacus;

- the different method of evaluation of thermal bridges does not involve significant discrepancies in the energy need per unit area of single apartments.

\section{Acknowledgements}

This research was funded by the research project PRA2017 - University of Genoa.

\section{References}

[1] Legislative Decree 19 August 2005, No. 192, Implementation of Directive 2002/91/EC on energy performance in buildings", 2005, Italy.

[2] European Parliament, Directive 2002/91/EC of The European Parliament and of the Council of 16 December 2002 on the energy performance of buildings. Official Journal of the European Union; 2003.

[3] European Parliament, Directive 2010/31/EU of The European Parliament and of the Council of 19 May on the energy performance of buildings (recast). Official Journal of the European Union; 2010.

[4] UNI/TS 11300-1, Energy Performance of Buildings, Part 1: Evaluation of Energy Need for Space Heating and Cooling, 2014, Italy.

[5] UNI EN ISO 10211, Thermal bridges in building constructions. Heat flows and surface temperatures. Detailed calculations, 2018.

[6] UNI EN ISO 14683, Thermal bridges in building construction. Linear thermal transmittance. Simplified methods and default values, 2018.

[7] Theodosiou T.G, Papadopoulos A.M. The impact of thermal bridges on the energy demand of buildings with double brick wall constructions, Energy and Buildings 40 (2008) 2083-2089. doi:10.1016/j.enbuild.2008.06.006

[8] UNI 10200, Centralized heating systems for space heating and domestic hot water production. Heating and domestic hot water costs sharing criteria, 2015, Italy.

[9] UNI 10351, Building materials and products. Hygrothermal proprieties. Procedure for determining the design values, 2015, Italy.

[10] UNI EN ISO 10456, Building materials and products. Hygrotherrnal properties. Tabulated design values and procedures for determining declared and design thermal values, 2008.

[11] UNI/TR 11552, Opaque envelope components of buildings. Thermo-physical parameters, 2014, Italy.

[12] UNI EN ISO 10077-1, Thermal Performance of Windows, Doors and Shutters. Calculation of Thermal Transmittance. Part 2: General, 2018.

[13] UNI EN ISO 6946, Building components and building elements. Thermal resistance and thermal transmittance. Calculation method, 2018.

[14] EDILCLIMA ${ }^{\circledR}$ Engineering \& Software, https://www.edilclima.it/

[15] UNI EN ISO 13790, Energy performance of buildings. Calculation of energy use for space heating and cooling, 2008.

[16] Capozzoli A., Corrado V., Gorrino A., Soma P., Thermal bridges national abacus according to UNI EN ISO 14683 and UNI EN ISO 10211 standards, EDIZIONI EDILCLIMA, 2011.

[17] THERM Finite Element Simulator (version 7.4.3.0). Lawrence Berkeley National Laboratory (LBNL), https://windows.lbl.gov/software /therm/therm.html.

[18] Bergero S, Cavalletti P, Chiari A., Energy refurbishment in existing buildings: Thermal bridge correction according to DM 26/06/2015 limit values, In: Energy Procedia 140 (2017) 127-140. doi:10.1016/j.egypro.2017.11.129

[19] Campodonico B., Building thermal bridges: classification, analytical calculation and energy comparison through a case study, Master's degree thesis, Department of Architecture and Design, 2018, Italy.

[20] Legislative Decree 19 July 2016, No. 141, Supplementary provisions to Legislative Decree 4 July 2014, n. 102, implementing Directive 2012/27/EU on energy efficiency, which amends the Directives 2009/125/EC and 2010/30/EU and repeals the Directives 2004/8/EC and 2006/32/EC, 2016, Italy. 